The temporal dominance of sensations method showed that four model dairy products had different dynamic profiles in terms of salt and texture perception. We investigated the physical origins of these differences, by studying the breakdown of these products and its impact on salt release. An experimental device was used for monitoring the kinetics of salt release from the food products into water -simulating saliva- after a standardized compression -simulating masticationindependently of the inter and intra individual variability. A mechanistic model was developed to quantify product breakdown in terms of the area of contact between the product and the aqueous phase. Fat had a major influence on breakdown behaviour and the calculated contact area that could be accounted for by the microstructure of the product. These results provide insight into the possible origins of differences in sensory perceptions of foods. We also discussed the use of this mechanistic model for modeling salt release in the conditions of food consumption.

\section{Mechanistic model of in vitro salt release from model dairy gels based on standardized breakdown test simulating mastication}

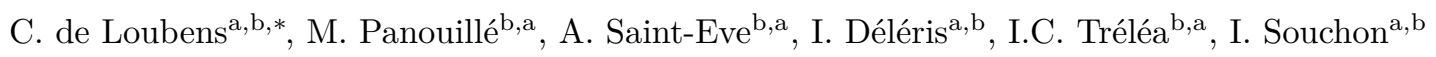 \\ ${ }^{a}$ INRA, UMR 782 Génie et Microbiologie des Procédés Alimentaires, CBAI 78850 Thiverval Grignon, France \\ ${ }^{b}$ AgroParisTech, UMR 782 Génie et Microbiologie des Procédés Alimentaires, CBAI 78850 Thiverval Grignon, \\ France
}

Keywords: cheese, dynamic, sensory, Temporal Dominance Sensation, texture, $\mathrm{NaCl}$

\section{Introduction}

Reducing the salt content of food has become a major concern for public health authorities worldwide. There is strong scientific evidence that dietary salt consumption is responsible for hypertension, which may result in cardiovascular disease, gastric cancer, osteoporosis, cataracts, kidney stones and diabetes (Organisation, 2007). The World Health Organisation therefore recommends limiting daily sodium chloride intake to $5 \mathrm{~g}$. Salt consumption may, however, be two or three times higher than this recommended level in some developed countries.

Reducing the salt or fat content of food is a major challenge for food manufacturers, because it often leads to a loss of organoleptic qualities. Food structure and texture affect aroma and taste perception (Phan et al. 2008; Saint-Eve et al., 2009; Koliandris et al., 2010, Panouillé et al., 2010),

\footnotetext{
${ }^{*}$ Corresponding author

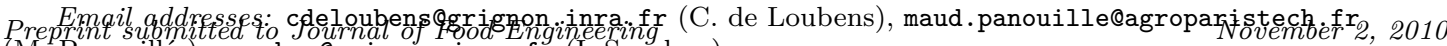
(M. Panouillé), souchon@grignon.inra.fr (I. Souchon)
} 
so one promising possibility is the tailoring of the food matrix to decrease salt content without decreasing the perception of saltiness. For example, liquid model cheeses were perceived as being more salty than gelled model cheeses (Panouillé et al. 2010). For gelled model cheeses, the degree of saltiness perceived depends on fat content(Panouillé et al., 2010). In this context, mechanistic models describing stimuli release during food consumption are of great interest, because they may make it possible to identify the most important physicochemical and physiological parameters responsible for this release (Harrison et al., 1998, Wright et al., 2003; Wright and Hills, 2003, Tréléa et al., 2008). Harrison et al. (1998) and Wright and Hills (2003) developed the first models of flavour release (i.e. the release of aroma compounds) from the chewed bolus. They demonstrated the importance of having detailed knowledge of the mastication process for the prediction of particle size distribution and of the contact areas between the product and the saliva and between the product and air. Food fragmentation can be modelled from empirical laws fitted to experimental data obtained in spit-out experiments (Kobayashi et al., 2006, 2010) or by statistical models considering mastication as a selection and breakdown process van der Bilt et al. 1987; Baragar et al. 1996, Harrison et al., 1998, Wright et al., 2003). From the distribution of chewing and swallowing time intervals measured by electromyography, Wright et al. (2003) simulated individual mastication patterns for use in flavour release calculations. However, to our knowledge, no model has yet been developed that takes into account the properties of the product for the prediction of particle size distribution and salt release in the mouth.

The objective of this study was so to quantify the breakdown of model dairy products in terms of contact areas independently of the individual variability of consumers.

Four model dairy products of different composition were chosen for study because they had already been extensively characterised, not only in terms of rheology and texture, but also in term of bolus formation (Panouillé et al. 2010, Drago et al., 2010). We first undertook a sensory characterisation of these dairy products. We characterised the dynamics of saltiness and texture perception, by generating temporal dominance of sensation (TDS) profiles for the four products. We then used an experimental device similar to those used in previous studies by Koliandris et al. (2008) and Mills et al. (2011), to measure salt release from product to water after breakdown in controlled conditions. A mechanistic model was developed for calculation of the contact area between the water and the product generated by compression. Finally, the results were discussed in terms of composition, structure and perception. We also discussed the use of this mechanistic model and methodology to model salt release in conditions of food consumption. 


\section{Materials \& Methods}

\subsection{Samples preparation}

Model cheeses were prepared as previously described by Saint-Eve et al. (2009): PL60 ultrafiltered skim milk retentate powder (Triballat, Noyal-sur-Vilaine, France), anhydrous milk fat (Corman, Goé, Belgium) and sodium chloride (Prolabo, France) were mixed. The pH was adjusted to 6.2 by adding glucono-delta-lactone (Sigma - Aldrich, Steinheim, Germany), rennet was added and the mixture was poured into containers and allowed to coagulate for $3 \mathrm{~h}$ at $30^{\circ} \mathrm{C}$. We used ultrafiltered skim milk retentate powder because the mineral composition of this product is similar to that of cow's milk, making it possible to avoid syneresis. Model cheeses were stored at $4^{\circ} \mathrm{C}$ overnight and experiments were carried out on the day after their preparation. We studied four model cheeses differing only in their fat content (0 or $40 \% \mathrm{w} / \mathrm{w}$, dry basis) and retentate powder concentration (150 or $250 \mathrm{~g} / \mathrm{kg}$ ). The other components remained constant: salt content $(1 \% \mathrm{w} / \mathrm{w})$ and $\mathrm{pH}$-value (6.2). Hereafter, we referred to the products as follows: PL 60 concentration $(\mathrm{g} / \mathrm{kg})(150$ or 250$) /$ fat content (\% dry basis, 0 or 40$)$. Table 1 summarizes the various compositions and notations for the four products.

\subsection{Sensory analysis}

The temporal perception of the four model cheeses was studied using the temporal dominance of sensation (TDS) method. Each panelist scored, over the course of time, the intensity of the descriptor perceived as dominant. TDS has been processed by 16 trained panelists, volunteer and motivated. For TDS measurement, seven attributes (moistness, softness, firmness, crumbliness, stickiness, fattiness and saltiness) were chosen, following the profile performed on the same products (Panouillé et al. 2010$)$. We used the same terms and definitions as in the previous study. All the attributes were presented simultaneously on a screen with a button. The panellists had to click on "start" when they placed a sample of the model cheese in the mouth and, during the evaluation, they were asked to select the attribute they considered to be dominant. If the dominant attribute change during the course of the trial, the subjects were asked to click on the new dominant attribute. For each panellist, we collected the following data during the consumption of each product: the time at which as attribute was identified as dominant and the name of the attribute concerned. During each run, the subjects were free to chew the sample as they wished. Samples were coded with three-digit random numbers and served in transparent plastic cups. Sample size was standardised at $5 \mathrm{~g}$. The four samples were assessed in duplicate, in random order, over two evaluation sessions. Data were acquired with Fizz software 
(Biosystèmes, 1990), in individual sensory booths under white light. TDS analysis was performed with Fizz Data Treatment. The dominance proportions were used to draw TDS curves over time, providing information about the descriptors considered dominant during the consumption period. Dominance proportions for an attribute $d^{a}$ were calculated by dividing the number of citations of this attribute $n_{c}^{a}$ by the number of judges $n_{j}$ and the number of replicate $n_{r}$, i.e $d_{a}=n_{c}^{a} /\left(n_{j} n_{r}\right)$. The sensory perceptions between panellists are close when the dominance rate is high. For each sample of model cheese, the dominance curves of all the descriptors are displayed on the same graph. Two other curves are also displayed to facilitate interpretation. The first, labelled as "chance" indicates the dominance proportion that an attribute would be expected to obtain by chance alone (1/number of attributes). The second curve, labelled "significance", indicates the smallest value of the proportion significantly higher than that expected by chance alone, in a binomial test. TDS curves above the significance level may be considered to be consistent across the panel (Pineau et al. 2009).

\subsection{Conductivity measurements}

Conductivity was measured with a conductivity probe (Heito, France). In addition to NaCl, the model cheese contained other solutes such as potassium, calcium, phosphates, citrates and lactates (Lauverjat et al., 2009; Floury et al., 2009). All these species contribute to the conductivity signal. With similar products, Lauverjat et al. (2009) showed that $\mathrm{NaCl}$ had mass transfer properties (diffusion and partition coefficients) similar to those of the other solutes. There is therefore no need to distinguish between the different solutes in this study. We use the term "salt" in this context to describe all the species contributing to the conductivity signal. The conductivity probe was thus calibrated at $37^{\circ} \mathrm{C}$, with aqueous $\mathrm{NaCl}$ solutions prepared with deionised water, and concentrations are given in $\mathrm{g} / \mathrm{L} \mathrm{NaCl}$ equivalent.

\subsection{Experimental set-up for product breakdown and salt release measurement}

A schematic diagram of the experimental set-up is shown in Figure 1] It consisted of a conductivity probe (Heito, France), a texturometer (TAXT2, Stable Microsystems) equipped with a Teflon probe $35 \mathrm{~mm}$ in diameter, a beaker of deionised water at $37^{\circ} \mathrm{C}(400 \mathrm{~mL})$, and a magnetic stirrer. On-line measurements of changes in conductivity began at time $\mathrm{t}=0$. At $\mathrm{t}=60 \mathrm{~s}$, a calibrated cylinder of product (12 $\mathrm{mm}$ height and $20 \mathrm{~mm}$ diameter, $\sim 3 \mathrm{~g}$ of product) was placed in the beaker. At $\mathrm{t}=150 \mathrm{~s}$, the product was compressed one or several times to a deformation level of $80 \%$ of the initial height. This compression took only $1 \mathrm{~s}$ in an overall experiment time of $400 \mathrm{~s}$. Conductivity registration was stopped at $t=400 \mathrm{~s}$. Similar experiments were carried 
out with no compression as controls, to assess the release of salt from intact product into water.

Three replicates were carried out per product.

\subsection{Partition coefficient of salt}

The water / product partition coefficients $K$ and initial salt concentrations $C_{p}^{0}$ of the four products were determined according to SL-PRV method developed by Lauverjat et al. (2009). The values of $K$ and $C_{p}^{0}$ are global and correspond to the total amount of salt present. The partition coefficients $K$ were comprised between 0.7 and 1 and the initial salt concentrations of the products $C_{p}^{0}$ were between $13 \mathrm{~g} / \mathrm{L}$ and $17 \mathrm{~g} / \mathrm{L}$.

\subsection{Mass transfer model}

Compression instantaneously generated a population of $n$ particles denoted $i$, where $i=\overline{1 . . n}$. For each particle, we note $V_{p i}$ its volume $\left(\mathrm{m}^{3}\right)$ and $A_{i}$ its contact area $\left(\mathrm{m}^{2}\right)$ with the surrounding volume of water $V_{w}\left(\mathrm{~m}^{3}\right)$. For processes occurring over a much shorter time scale than diffusion, the most mathematically tractable option is to consider salt release to be described by a mass transfer coefficient $k_{p}(\mathrm{~m} / \mathrm{s})$ and to consider the solute concentration of each piece $C_{p i}$ to be uniform. Changes in the salt concentration of the water $C_{w}$ is therefore given by a mass balance between the product and the water:

$$
V_{w} \frac{d C_{w}}{d t}=k_{p} \sum_{i=1}^{n} A_{i}\left(K . C_{p i}(t)-C_{w}(t)\right)
$$

where $t$ is the time $(\mathrm{s})$ and $K$ is the water / product partition coefficient given by the ratio of the salt concentration at the equilibrium between the water $C_{w}^{e q}$ and the product $C_{p}^{e q}$ :

$$
K=\frac{C_{w}^{e q}}{C_{p}^{e q}}
$$

The salt release from each particle of product is given by:

$$
V_{p i} \frac{d C_{p i}}{d t}=-k_{p} A_{i}\left(K . C_{p i}(t)-C_{w}(t)\right) \text { for } i=\overline{1 . . n}
$$

This model is not tractable in practice. We therefore simplified these equations to generate two usable models.

\section{Model 1: particles of uniform size}

If the duration of the experiment is very short with respect to the time scale of the mass transfer from the product to the water (i.e. $t \ll V_{p i} / k_{p} A_{i}$ whatever $i$ ), the concentrations in each piece of product are similar and the population of pieces is equivalent to one product piece 
of volume $V_{p}=\sum_{i=1}^{n} V_{p i}$, of contact area $A=\sum_{i=1}^{n} A_{i}$ and of salt concentration $C_{p}$ (Figure 2). Equations 1 and 3 can be reduced to:

$$
\begin{gathered}
V_{w} \frac{d C_{w}}{d t}=k_{p} A\left(K . C_{p}(t)-C_{w}(t)\right) \\
V_{p} \frac{d C_{p}}{d t}=-k_{p} A\left(K . C_{p}(t)-C_{w}(t)\right)
\end{gathered}
$$

The initial conditions are given by the salt concentration in water at $t_{0}=150 \mathrm{~s}$ and the initial concentration in the product $C_{p}^{0}$ :

$$
\begin{aligned}
& C_{w}\left(t_{0}\right)=C_{w}^{0} \text { at } t_{0}=150 \mathrm{~s} \\
& C_{p}\left(t_{0}\right)=C_{p}^{0} \text { at } t_{0}=150 \mathrm{~s}
\end{aligned}
$$

$C_{p}^{0}$ and $K$ were determined by the solid-liquid phase ratio variation method (SL-PRV) (Lauverjat et al. 2009). The contact area $A$ and the mass transfer coefficient $k_{p}$ were unknown $a$ priori. The value of $k_{p}$ was obtained for each product by fitting this model to the kinetics of salt release measured in water $C_{w}(t)$ in the absence of compression ("control test"). The contact area $A_{0}$ was calculated from the initial sample geometry $\left(A_{0}=10.7 \mathrm{~cm}^{2}\right)$. Knowing $k_{p}, A$ was then determined by fitting the model to $C_{w}(t)$ measured during the compression tests. Regression analysis was carried out with Matlab 7 (The Mathworks, Natick, MA).

Model 2: particles of non-uniform size

If the size distribution of a population of particles is broad, then the the uniform-size model does not correctly represent salt release because the time scale of the mass transfer from the smallest particles to the water is equivalent to the duration of the experiment (i.e. there is $i$ such that $\left.t \sim V_{p i} / k_{p} A_{i}\right)$. A second model was developed and applied to a single product generating particles of heterogeneous size (250/40). Compression was considered to generate two populations of particles with volumes $V_{p 1}$ and $V_{p 2}$, contact areas $A_{1}$ and $A_{2}$ and salt concentration $C_{p 1}$ and $C_{p 2}$ (Figure 2). The mass balances of salt in water involve two terms representing the flux of salt from each piece of product. Thus, we have:

$$
V_{w} \frac{d C_{w}}{d t}=k_{p} A_{1}\left(K . C_{p 1}(t)-C_{w}(t)\right)+k_{p} A_{2}\left(K . C_{p 2}(t)-C_{w}(t)\right)
$$

The mass balances in each volume are: 


$$
\begin{gathered}
V_{p 1} \frac{d C_{p 1}}{d t}=-k_{p} A_{1}\left(K . C_{p 1}(t)-C_{w}(t)\right) \\
V_{p 2} \frac{d C_{p 2}}{d t}=-k_{p} A_{2}\left(K . C_{p 2}(t)-C_{w}(t)\right)
\end{gathered}
$$

The initial conditions are:

$$
\begin{aligned}
& C_{w}\left(t_{0}\right)=C_{w}^{0} \text { at } t_{0}=150 \mathrm{~s} \\
& C_{p 1}\left(t_{0}\right)=C_{p}^{0} \text { at } t_{0}=150 \mathrm{~s} \\
& C_{p 2}\left(t_{0}\right)=C_{p}^{0} \text { at } t_{0}=150 \mathrm{~s}
\end{aligned}
$$

Fitting the model to the experimentally measured salt kinetics $C_{w}(t)$, we were able to determine $A_{1}, A_{2}, V_{p 1}$ and $V_{p 2} . \quad k_{p}$ was determined with Model 1 based on the test without compression ("control test").

\subsection{Data analysis}

One-way analysis of variance (ANOVA) on mass transfer coefficients $k_{p}$ and on total contact area $A$ with the products as factor were performed (Matlab7.0). When significant product differences were observed $(\mathrm{p}<0.05)$, the results were compared using a multiple comparison test (Matlab7.0).

\section{Results}

\subsection{Sensory analysis}

The TDS curves (Figure 3) show, for each product, the dominant attribute perceived at each time point during the trial, for the panel as a whole. For products with high levels of protein, 
the 250/40 product was perceived as crumbly from $2 \mathrm{~s}$ to $6 \mathrm{~s}$ and soft from $2 \mathrm{~s}$ to $17 \mathrm{~s}$. It was then perceived salty from $13 \mathrm{~s}$ to $28 \mathrm{~s}$ with a maximum around $18 \mathrm{~s}$. 250/0 was perceived moist, soft, crumbly and then salty from $14 \mathrm{~s}$ to $25 \mathrm{~s}$ (later and for a shorter period than for 250/40). Products with low protein levels (150/0 and 150/40) were perceived as being soft and moist. The $150 / 0$ product was perceived as salty from $11 \mathrm{~s}$ to $25 \mathrm{~s}$, whereas $150 / 40$ was perceived as being dominant salty from $6 \mathrm{~s}$ to $30 \mathrm{~s}$. The presence of fat therefore led to the earlier perception of saltiness and a longer duration of this perception during the consumption of model dairy products. After $32 \mathrm{~s}$, the TDS curves for all products were below the significance limit, indicating a lack of consensus concerning the dominant attribute.

\subsection{Influence of compression parameters on the release kinetics}

For the selection of appropriate parameters for use in the breakdown test, we assessed the influence of the compression parameters on the salt release kinetics for one product $(250 / 40)$. The parameters considered were probe velocity $(1 \mathrm{~mm} / \mathrm{s}$ or $10 \mathrm{~mm} / \mathrm{s})$, level of strain $(50$ or $80 \%)$ and the number of compression cycles ( 1 or 5 cycles). Figure 4 shows the kinetics obtained.

Effect of probe velocity

The velocity of the probe had no great impact on the release kinetics: curves were shifted to the right only for the lowest velocity $(1 \mathrm{~mm} / \mathrm{s})$. Breakdown occurred $10 \mathrm{~s}$ later for a probe velocity of $1 \mathrm{~mm} / \mathrm{s}$ than for a velocity of $10 \mathrm{~mm} / \mathrm{s}$ (i.e. at $190 \mathrm{~s}$ rather than $150 \mathrm{~s}$ ). The kinetics followed a similar pattern after this time point for both velocities. A velocity of $10 \mathrm{~mm} / \mathrm{s}$ is closer to the conditions of natural mastication (Finney and Meullenet, 2005) and was therefore retained for subsequent experiments.

Effect of the level of strain

Strain level affects salt release kinetics. Salt release was more rapid at $80 \%$ strain than at $50 \%$ strain (Figure 4). This difference is further accounted for by the greater contact area at higher levels of strain, due to the greater product breakdown. The fracture strain of this product is about $80 \%$ (Panouillé et al. 2010). Thus, at 50\% strain, the product is broken up into larger particles, which therefore have a smaller area of contact with the water. During mastication, the jaws and tongue impose high levels of strain. We therefore retained the $80 \%$ strain level for subsequent experiments.

Effect of the number of compression cycles

The last parameter tested was the number of compression cycles ( 1 or 5 cycles). This parameter had no effect on salt release kinetics (Figure 4). Indeed, the product was fully broken 
up after the first compression cycle.

These preliminary tests made it possible to select the compression parameters: a probe velocity of $10 \mathrm{~mm} / \mathrm{s}$, a strain level of $80 \%$ and one compression cycle were retained for subsequent experiments.

\section{Effect of compression}

Figure 5 presents typical patterns of salt release for two products (250/0 and 250/40) without compression ("control test") and with compression (probe velocity: $10 \mathrm{~mm} / \mathrm{s}$, strain level: $80 \%$, one cycle of compression). In the absence of compression, salt was released slowly and continuously. By contrast, compression with a strain level of $80 \%$ significantly accelerated salt release, from $150 \mathrm{~s}$ onwards, due to the breakdown of the product and the generation of a greater contact area between product and water.

\subsection{Effect of the product contact area generation}

Mass transfer coefficient

Model 1 was first fitted to the salt release kinetics in the absence of compression ("control test"), making it possible to calculate the mass transfer coefficients $k_{p}$. These coefficients ranged between 2 and $3 \cdot 10^{-6} \mathrm{~m} / \mathrm{s}$. The product had no significant effect on the mass transfer coefficient $(\mathrm{p}>0.05)$.

\section{Effect of compression on contact area}

By fitting model 1 (particles with uniform size) to the salt release kinetics after compression, we were able to determine the contact area generated by the compression. Figure 6ra presents the pattern of salt release from the time at which compression occurred (150 s) until the end of the experiments for three products $(250 / 0,150 / 0,150 / 40)$ and the fitted release models. For these products, model 1 fit the data well: the measurement time was short enough to consider that the population of particles is equivalent to one piece of product. Figure 6 $6 \mathrm{~b}$ shows the kinetics obtained for 250/40. Model 1 fitted the data poorly. We therefore used only model 2 (non uniform size distribution) for this product. In this case, salt release slowed 50 seconds after the compression (at $\mathrm{t}=200 \mathrm{~s}$ ). Salt release was initially rapid, due to the contribution of all particles. We can therefore show, from the general model, that the slope of the curve at the origin is proportional to the total amount of product/water contact area $A$. Salt release was subsequently lower and due exclusively to release from the largest particles.

The contact areas generated by compression are shown on Figure 7 They were about 100 $\mathrm{cm}^{2}$ for $250 / 40$ and 20 to $30 \mathrm{~cm}^{2}$ for the others products $(150 / 0,150 / 40,250 / 0)$. These areas 
are about 10 times and 2 times larger, respectively, than the initial sample area. The 250/40 product behaved markedly differently from the other products. Statistical analysis confirmed a strong product effect $(\mathrm{p}<0.0001)$ and distinguished two different classes of products: one class consisting of 250/40 and the other consisting of the other three products.

Visual inspection of the products after compression (Figure 8) confirmed these results: 250/40 was fragmented into smaller pieces than the other products.

\section{Discussion}

\subsection{Effect of product structure and composition on breakdown}

The composition of the product affected the contact area generated by strong compression. Fat content had a strong effect for high dry matter, with 250/40 having a contact area 3.5 times that for $250 / 0$.

In a previous study with a similar experimental device, Koliandris et al. (2008) obtained a good negative correlation between $\mathrm{Na}^{+}$concentration at a given time (20 $\mathrm{s}$ after the breakdown) and the strain rupture of gels. However, it seems difficult to relate the salt release kinetics with a strain or stress rupture because salt release is dependent principally on the contact area generated by product breakdown, which is related to product microstructure and the propagation of cracks within the sample (Gunasekaran and $\mathrm{Ak}, 2003)$.

The observations reported here can be accounted for by product microstructure. Panouillé et al. (2010) characterised the rheological behaviour and the microstructure of the products used in this study. Measurements under small-amplitude oscillations showed that all these products displayed a gel-like behaviour (G'>G", almost constant at all frequencies). All products had a fracture strain lower than $80 \%$ and were therefore fractured during the compression. The microstructure of the products was characterised by confocal laser scanning microscopy. Panouillé et al. (2010) showed that for all products, after gel formation, there was a visible protein network that was denser for the 250 products than for the 150 products. For $250 / 40$ and 150/40, the fat was concentrated within the protein network and was almost absent from the serum phase. For 250/40, a few flocculated and coalesced fat globules were observed. These results may account for the differences in contact area generated by compression. The concentration of the fat within the protein network may have weakened the protein network, facilitating the propagation of the fracture through the sample and resulting in the generation of smaller particles. However, this effect of fat depends on the processes used to manufacture the product, which should be investigated, along with other technological processes. 


\subsection{Breakdown and sensory properties}

For the products tested here, Panouillé et al. (2010) observed that the perception of saltiness increased with fat content. Indeed, a greater fat content leads to the generation of a larger contact area on compression, resulting in higher levels of salt release. We can assume that the breakdown pattern in the mouth is similar to that observed in vitro and that salt is released more rapidly from fat-containing samples than from fat-free samples.

The results obtained by TDS analysis support this hypothesis. For 250/40, crumbly was the dominant attribute perceived (Figure 3). This sensation was identified as dominant immediately after the introduction of the product into the mouth for $250 / 40$, whereas it was identified as the dominant attribute $6 \mathrm{~s}$ later for 250/0. This suggests that 250/40 was more quickly fractionated by mastication than the other products, creating a greater contact area with saliva and resulting in the more rapid release of salt.

\subsection{Modeling breakdown and salt release during food consumption}

In addition to an analysis of the effects of dairy product composition and structure on the breakdown of these products, this study constitutes the first step towards the modeling of salt release during food consumption.

During mastication, the product is fractured by action of the teeth and tongue actions, resulting in the generation of particles. To model aroma compounds release during food consumption, Harrison et al. (1998) and Wright et al. (2003) calculated the particle size distribution. However, if the duration of the mastication is very short compared to the time scale of the mass transfer from the product to the water, as demonstrated in our study, the salt release can be modeled simply with a mass transfer coefficient, without the need for knowledge concerning the size distribution of the particles. The main parameter to be determined is the area of contact between the particles and the saliva. During food consumption, the food is masticated for about $30 \mathrm{~s}$ (mean time observed for the products used in this study). The model considering the population of particles to be equivalent to one product piece of volume $V_{p}$, of contact area $A$ and of salt concentration $C_{p}$ (Model 1: uniform size particles) fitted the data well, for three products (Figure 5). For the last product $(250 / 40)$, as shown Figure 9 model 1 simulated well the experimental data for times of less than approximately $50 \mathrm{~s}$ when the area of contact is those estimated thanks to the model 2. For this product, after $50 \mathrm{~s}$, the model 1 overestimated the salt release kinetics. Thus, the model 1 could be used to model salt release during food consumption for this kind of products because the mastication duration is shorter than $50 \mathrm{~s}$. The main differences between 
the conditions in vitro and in vivo are dilution by saliva (dependent on the saliva flow rate) and the changes in contact area occurring during mastication.

\section{Conclusion}

The experimental device and the mechanistic model developed here made it possible to measure the contact area generated by compression for several model dairy products and to account for the impact of gel structure on salt release. The model developed constitutes a first step towards the modeling of salt release during food consumption and the contact area measured under control conditions provides information about the fracture properties of the material.

Product composition and microstructure affect the breakdown of the product and the sensory perceptions. The food consumption and the sensory perceptions involve a set of variables that can not be reproduced at laboratory scale. However, the models and the experimental device developed in this study are approximations which considers some important variables of the mastication process. Thanks to their relative simplicity in term of use, they could be used to guide the product formulation.

Finally, this study shows that tailoring the microstructure of the product to control product breakdown in the mouth is one possible way in which the release and perception of stimuli could be improved.

\section{References}

Baragar, F., van der Bilt, A., van der Glas, H., 1996. An analytic probability density for particle size in human mastication. Journal of Theoretical Biology 181 (2), 169-178.

Drago, S.R., Panouillé, M., Saint-Eve, A., Neyraud, E., Feron, G., Souchon, I., 2010, Relationships between saliva and food bolus properties from model dairy products. Food Hydrocolloids, In Press, Corrected Proof, doi: 10.1016/j.foodhyd.2010.07.024.

Finney, M., Meullenet, J.F., 2005. Measurement of biting velocities at predetermined and individual crosshead speed instrumental imitative tests for predicting sensory hardness of gelatin gels. Journal of Sensory Studies 20 (2), $114-129$.

Floury, J., Rouaud, O., Poullennec, M. L., Famelart, M.-H., 2009. Reducing salt level in food: Part 2. modelling salt diffusion in model cheese systems with regards to their composition. LWT - Food Science and Technology 42 (10), 1621 - 1628. 
Gunasekaran, S. and Ak, M., 2003. Cheese rheology and texture. CRC Press.

Harrison, M., Campbell, S., Hills, B., 1998. Computer simulation of flavor release from solid foods in the mouth. Journal of Agricultural and Food Chemistry 46 (7), 2736-2743.

Kobayashi, N., Kohyama, K., Sasaki, Y., Matsushita, M., 2006. Statistical laws for food fragmentation by human mastication. Journal of the Physical Society of Japan 75 (8), 083001.

Kobayashi, N., Kohyama, K., Shiozawa, K., 2010. Fragmentation of a Viscoelastic Food by Human Mastication. Journal of the Physical Society of Japan 79 (4), 044801.

Koliandris, A., Lee, A., Ferry, A.-L., Hill, S., Mitchell, J., 2008. Relationship between structure of hydrocolloid gels and solutions and flavour release. Food Hydrocolloids 22 (4), 623-630.

Koliandris, A.-L., Morris, C., Hewson, L., Hort, J., Taylor, A. J., Wolf, B., 2010. Correlation between saltiness perception and shear flow behaviour for viscous solutions. Food Hydrocolloids 24(8), 792-799.

Lauverjat, C., de Loubens, C., Déléris, I., Tréléa, I. C., Souchon, I., 2009. Rapid determination of partition and diffusion properties for salt and aroma compounds in complex food matrices. Journal of Food Engineering 93 (4), 407-415.

Mills, T., Spyropoulos, F., Norton, I. T., Bakalis, S., 2011. Development of an in-vitro mouth model to quantify salt release from gels. Food Hydrocolloids 25, 107-113.

Organisation, W. H., 2007. Reducing salt intake in populations. In: WHO Document Production Services, G. (Ed.), Report of a WHO Forum and Technical Meeting.

Panouillé, M., Saint-Eve, A., de Loubens, C., Déléris, I., Souchon, I., 2010. Understanding of the influence of composition, structure and texture influence salty perception in model dairy products. Food Hydrocolloids In Press, Corrected Proof, doi:10.1016/j.foodhyd.2010.08.021.

Phan, V., Yven, C., Lawrence, G., Chabanet, C., Reparet, J., Salles, C., 2008. In vivo sodium release related to salty perception during eating model cheeses of different textures. International Dairy Journal 18 (9), 956 - 963.

Pineau, N., Schlich, P., Cordelle, S., Mathonnière, C., Issanchou, S., Imbert, A., Rogeaux, M., Etiévant, P., Köster, E., 2009. Temporal dominance of sensations: Construction of the tds curves and comparison with time-intensity. Food Quality and Preference 20 (6), 450 - 455. 
Saint-Eve, A., Lauverjat, C., Magnan, C., Deleris, I., Souchon, I., 2009. Reducing salt and fat content: Impact of composition, texture and cognitive interactions on the perception of flavoured model cheeses. Food Chemistry 116 (1), 167-175.

Tréléa, I., Atlan, S., Déléris, I., Saint-Eve, A., Marin, M., Souchon, I., 2008. Mechanistic mathematical model for in vivo aroma release during eating of semiliquid foods. Chemical Senses $33(2), 181-192$.

van der Bilt, A., Olthoff, L., van der Glas, H., van der Weelen, K., Bosman, F., 1987. A mathematical description of the comminution of food during mastication in man. Archives of Oral Biology $32(8), 579-586$.

Wright, K., Hills, B., 2003. Modelling flavour release from a chewed bolus in the mouth: Part II. The release kinetics. International Journal of Food Science and Technology 38 (3), 361-368.

Wright, K., Sprunt, J., Smith, A., Hills, B., 2003. Modelling flavour release from a chewed bolus in the mouth: Part I. Mastication. International Journal of Food Science and Technology $38(3), 351-360$. 
380

381

382

383

384

385

386

387

388

389

390

391

392

393

394

395

396

397

398

399

400

401

402

403

404

Tables and Figures

List of Tables

$1 \quad$ Code and composition of the model dairy products. . . . . . . . . . . . . . . . . 17

\section{List of Figures}

$1 \quad$ Schematic diagram of the experimental set-up for the breakdown test. . . . . . . . 18

$2 \quad$ Principles and notations of the salt release models. Model 1 (left) considers the population of particles to be equivalent to one piece of product. Model 2 (right) considers the particle distribution to be approximated by two pieces of product of different sizes. . . . . . . . . . . . . . . . . . . . . . . . . . . . . . . . 19

3 Temporal dominance of sensation (TDS) curves (dominance rate as a function of time) of the 4 products : $250 / 40,250 / 0,150 / 40,150 / 0 . \ldots \ldots \ldots 20$

$4 \quad$ Influence of compression parameters (i.e. probe velocity, strain level, number of compression cycles) on the salt release kinetics from model dairy gels during the breakdown test $(250 / 40): 10 \mathrm{~mm} / \mathrm{s}, 80 \%, 1$ cycle $(\bullet) ; 1 \mathrm{~mm} / \mathrm{s}, 80 \%, 1$ cycle $(\bullet)$ $\ldots ; 10 \mathrm{~mm} / \mathrm{s}, 50 \%, 1$ cycle $(\mathbf{\square}) ; 10 \mathrm{~mm} / \mathrm{s}, 80 \%, 5$ cycles $(\mathbf{\Lambda}) . \ldots \ldots \ldots 21$ a 5 Salt release kinetics during the breakdown test for two products (250/40 in black and 250/0 in grey) after compression (solid lines) and their associated control tests (no compression, dotted lines): probe velocity: $10 \mathrm{~mm} / \mathrm{s}$, strain level: $80 \%$, one cycle of compression. . . . . . . . . . . . . . . . . . . . 22

\ 6 Experimental data and release model simulation. (a) Experimental data for 3 products $(\triangle 250 / 0, \mathrm{O} 150 / 40, \square$ 150/0) and model 1 fittings (particles of uniform size, solid lines). (b) Experimental data for 1 product $(\diamond 250 / 40)$, model 1 fitting (particles of uniform size, solid line) and model 2 fitting (particles of non-uniform size, dotted lines). For 250/40 model 2 was used to determine the contact area generated during the breakdown test due to the poor agreement of the model 1 with the experimental data. . . . . . . . . . . . . . . . . . 23

7 Contact area between the product and the water after compression for the various products studied. . . . . . . . . . . . . . . . . . . . . . 24

8 Model dairy products after the breakdown test. $A$ is the area of contact between the product and the water calculated with the models. . . . . . . . . . . . . 25 
${ }_{405}^{4} \quad 9 \quad$ Experimental data $(\triangle)$ and release model simulations for 250/40: model 2 fitted

${ }_{406}$ on the experimental data to determine the contact area generated during the

407 breakdown test (dotted line); model 1 simulated with the contact area determined

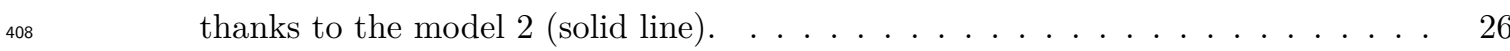




\begin{tabular}{ccccc}
\hline Code & $\begin{array}{c}\text { Milk retentate powder } \\
{[\mathrm{g} / \mathrm{kg}]}\end{array}$ & $\begin{array}{c}\text { Anhydrous milk fat } \\
{[\mathrm{g} / 100 \mathrm{~g} \mathrm{DM}]}\end{array}$ & $\begin{array}{c}\text { Rennet } \\
{[\mathrm{g} / \mathrm{kg}]}\end{array}$ & $\begin{array}{c}\text { Water } \\
{[\mathrm{g} / \mathrm{kg}]}\end{array}$ \\
\hline $250 / 40$ & 250 & 40 & 1.27 & 573 \\
$250 / 0$ & 250 & 0 & 1.27 & 740 \\
$150 / 40$ & 150 & 40 & 0.78 & 740 \\
$150 / 0$ & 150 & 0 & 0.78 & 850 \\
\hline
\end{tabular}

Table 1: Code and composition of the model dairy products. 


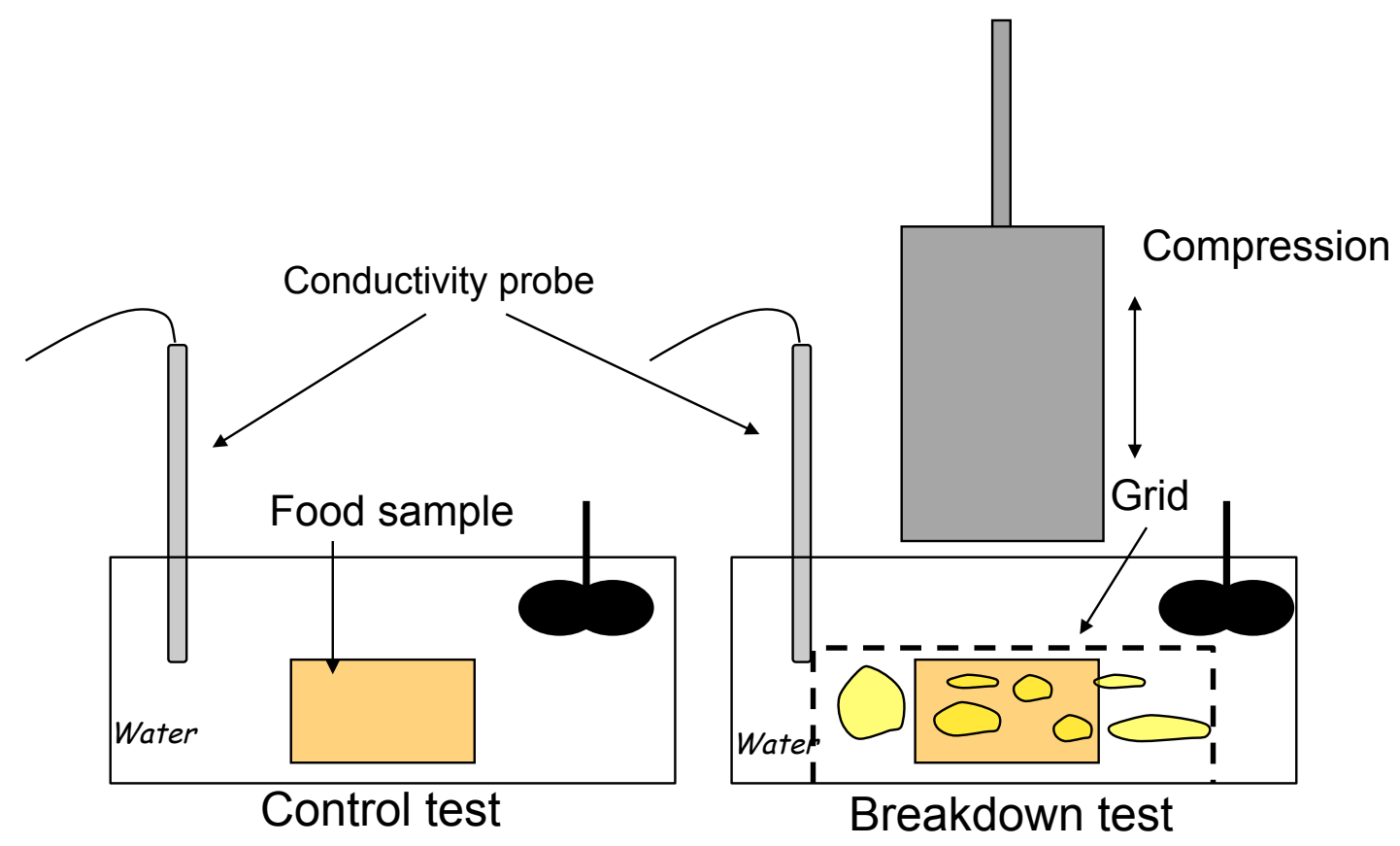

Figure 1: Schematic diagram of the experimental set-up for the breakdown test. 


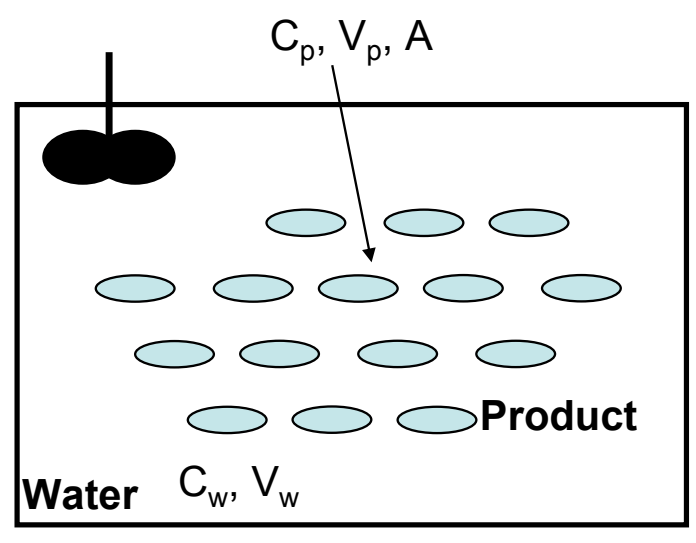

Model 1:

Particles with unifrom size

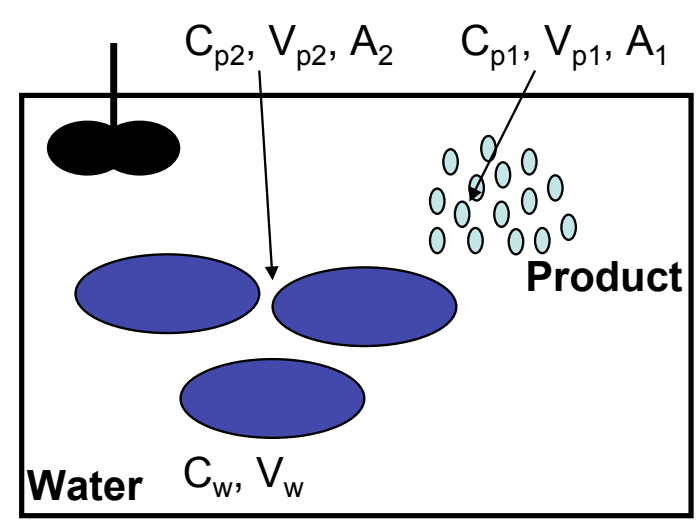

Model 2:

Particles with non-unifrom size

Figure 2: Principles and notations of the salt release models. Model 1 (left) considers the population of particles to be equivalent to one piece of product. Model 2 (right) considers the particle distribution to be approximated by two pieces of product of different sizes. 

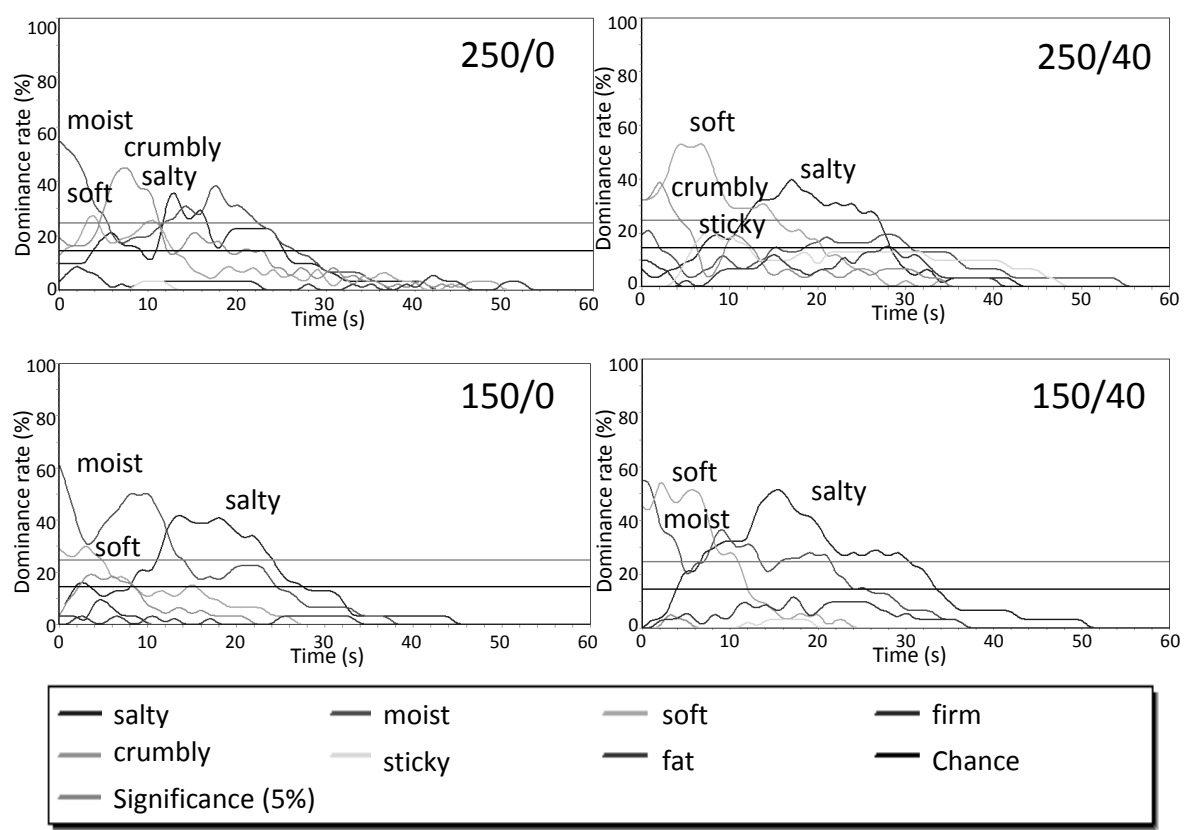

Figure 3: Temporal dominance of sensation (TDS) curves (dominance rate as a function of time) of the 4 products : 250/40, 250/0, 150/40, 150/0. 


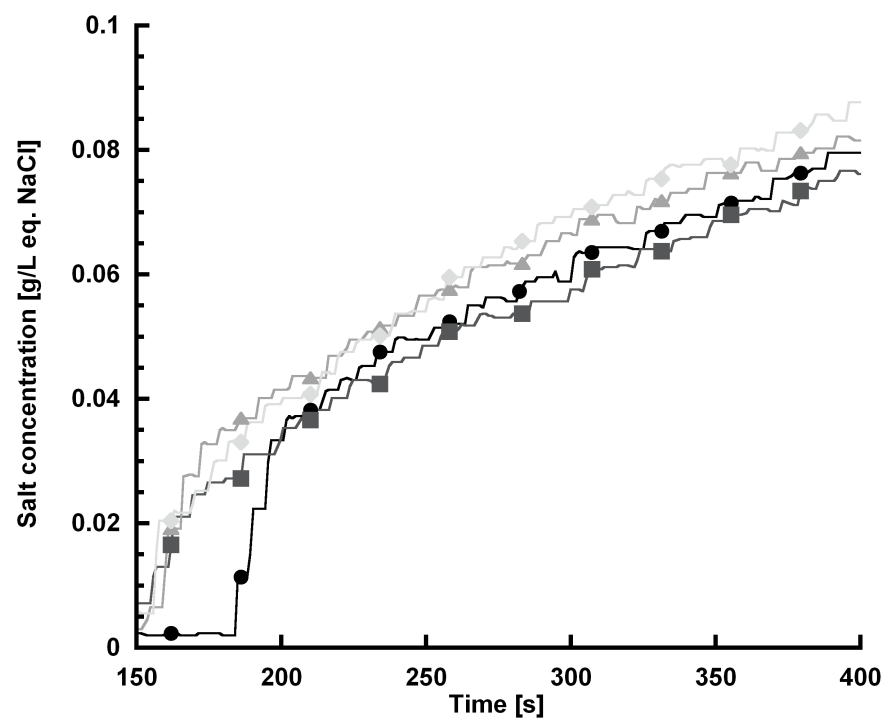

Figure 4: Influence of compression parameters (i.e. probe velocity, strain level, number of compression cycles) on the salt release kinetics from model dairy gels during the breakdown test (250/40): $10 \mathrm{~mm} / \mathrm{s}, 80 \%, 1 \mathrm{cycle}(\boldsymbol{})$; $1 \mathrm{~mm} / \mathrm{s}, 80 \%, 1$ cycle $(\bullet) ; 10 \mathrm{~mm} / \mathrm{s}, 50 \%, 1$ cycle $(\boldsymbol{\square}) ; 10 \mathrm{~mm} / \mathrm{s}, 80 \%, 5$ cycles $(\boldsymbol{\Delta})$. 


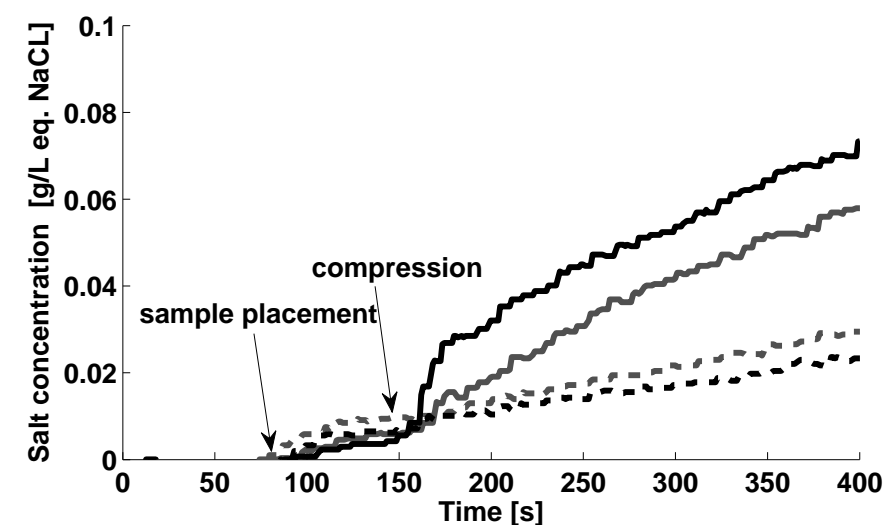

Figure 5: Salt release kinetics during the breakdown test for two products (250/40 in black and 250/0 in grey) after compression (solid lines) and their associated control tests (no compression, dotted lines): probe velocity: $10 \mathrm{~mm} / \mathrm{s}$, strain level: $80 \%$, one cycle of compression. 

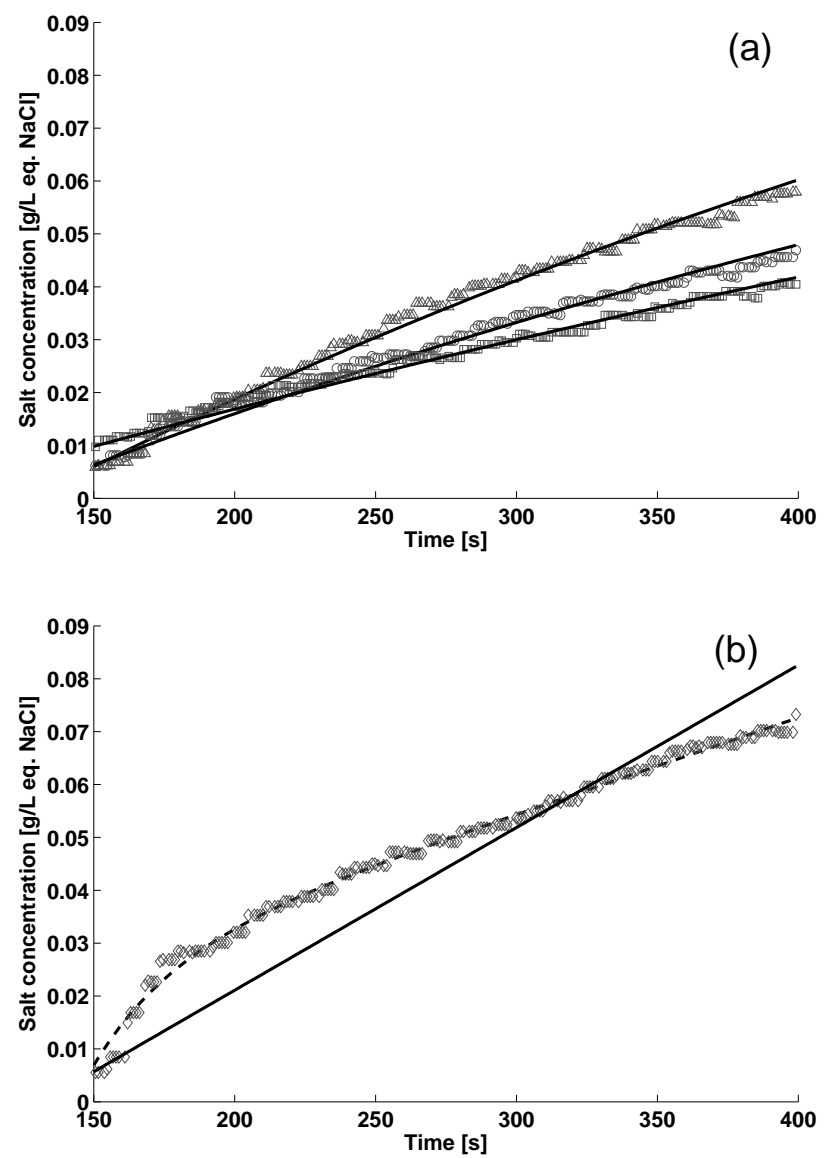

Figure 6: Experimental data and release model simulation. (a) Experimental data for 3 products $(\triangle 250 / 0, \mathrm{O}$ 150/40, $\square$ 150/0) and model 1 fittings (particles of uniform size, solid lines). (b) Experimental data for 1 product $(\diamond 250 / 40$ ), model 1 fitting (particles of uniform size, solid line) and model 2 fitting (particles of non-uniform size, dotted lines). For 250/40 model 2 was used to determine the contact area generated during the breakdown test due to the poor agreement of the model 1 with the experimental data. 


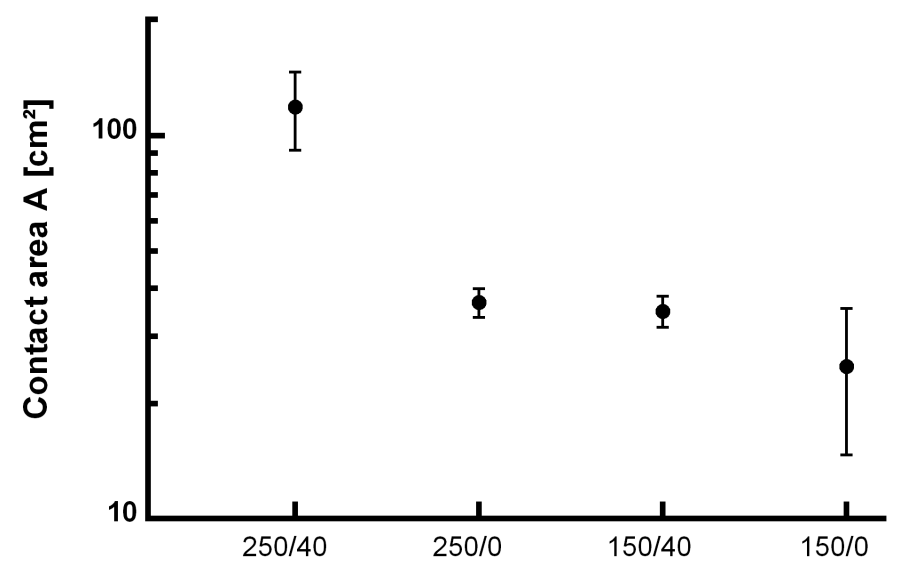

Figure 7: Contact area between the product and the water after compression for the various products studied. 


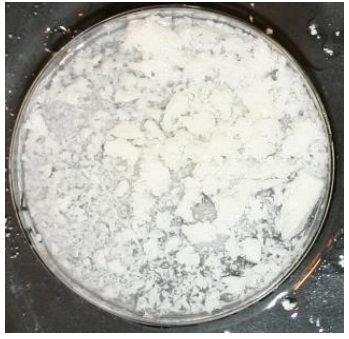

$250 / 40$

$A=119+/-27 \mathrm{~cm}^{2}$

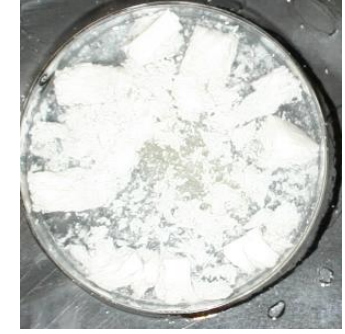

$150 / 40$

$A=34+/-3 \mathrm{~cm}^{2}$

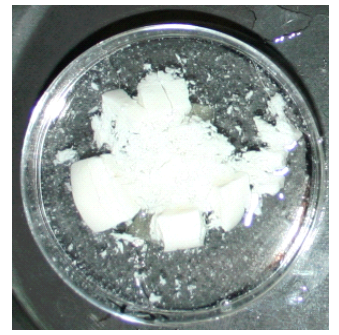

$250 / 0$

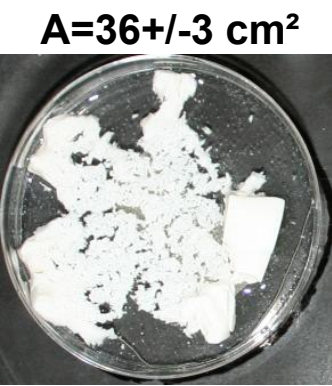

$150 / 0$

$A=25+/-10 \mathrm{~cm}^{2}$

Figure 8: Model dairy products after the breakdown test. $A$ is the area of contact between the product and the water calculated with the models. 
K 